\title{
Örgütsel Sıkılık-Esnekliğin Sosyal Kaytarma Alg1sı ve Yenilikçiliğe Olan Etkileri: Akademisyenler Üzerinde Bir Araştırma
}

\author{
Arzu UĞURLU KARA* \\ Memduh BEGENİRBAŞ** (i)
}

\section{ÖZ}

Günümüz rekabetçi dünyasında örgütler hayatta kalabilmek ve rekabette avantaj sağlayabilmek için, sosyo-kültürel alanlardaki değişimleri de yakından takip etmelidir. Aynı zamanda örgütler stratejilerini yaşanan değişimlere uyumlaştırabilmelidir. Farklı toplumlarda, farklı örgütlerde hatta farklı gruplarda bulunan bireylerin olayları algılama biçimleri de farklıdır. Bu farklılı̆̆ın oluşmasındaki temel taşlardan birisi de sahip olunan kültürel yapıdır. Örgüt içinde çalışan bireyler, diğerleriyle birlikte çalışmasının sonucu olarak birtakım tutum ve davranışlar geliştirebilir. Sosyal kaytarma eğilimi de bunlardan bir tanesidir. Gerekirse örgütlerde algılanan kültür yapısı bu kaytarma davranışını engelleyecek, kişilerin gerçek kapasitelerini ortaya çıkaracak ve bunu örgüt yararına kullanabilecek șekilde oluşturulmalıdır. Aynı zamanda bu kültürel algı kişilerin ve örgütün yenilikçi davranma eğilimlerinin de çerçevesini çizebilecektir. Kişilerin kararlara katılabildiği, yaratıcılı̆̆ın desteklendiği ve ödüllendirildiği yapılarda çalışanlar daha yenilikçi davranabilecektir.

Bilimsel ve teknolojik alandaki yenilikçiliği yakından takip eden, risk alabilen, değissen çevresel koşullara uyum gösterebilen yapıların başarılı olma ihtimali daha yüksek olacaktır. Yükseköğretim kurumlarının bilgiyi üretme ve paylaşma hususundaki yapacakları yeniliklerin ve bunların takibinin eğitim sürecine olumlu katkılarda bulunacağı değerlendirilmektedir. Bu durumda üniversitelerdeki yöneticilerin kurumlarının sahip olduğu kültürel yapı ışı̆̆ında, yeniliğe bakışı açıları ve destekleme oranları, risk alabilmeleri, herkesten eşit özveri ve çalışma disiplini bekleyerek herkesi bu sürece dahil edebilmeleri önem arz edecektir. Bu araştırma ile de akademisyenlerin kurumlarındaki sıkı ve esnek örgüt kültürü algılarının, yenilikçi davranışlarını ve birliktelikten doğan olası kaytarma eğilimlerini nasıl etkilediği araștırılmıștır.

Araştırma Ankara ilinde bulunan bazı üniversitelerde çalışan 236 akademisyenden kolayda örnekleme yöntemiyle toplanan verilerin analiziyle gerçekleștirilmiștir. S1kılık-Esneklik algısını ölçmek için Gelfand ve arkadaşlarının (2006) geliștirdiği ve Özeren'in (2011) Türkçe'ye uyarladığ1 6 sorudan oluşan ölçek, Sosyal Kaytarma algısını ölçmek için Mulvey ve Howard (1998) ile George'nin (1992) çalışmalarından uyarlanan, Șeșen ve Kahraman (2014) tarafindan Türkçe'ye çevrilen 4 sorudan oluşan ölçek , Yenilikçilik eğilimini ölçmek için (Jong, 2007) tarafindan geliştirilen, Köksal vd. (2018) tarafindan Türkçeye uyarlanan 10 sorudan oluşan ölçek kullanılmıștır. Ölçeklerden uygun olan "kesinlikle katılmıyorum" (1), "katılmıyorum" (2), "kararsızım" (3), "katılıyorum" (4) ve "kesinlikle katıllyorum" (5) değerlerine karşlık gelen 5'li Likert ölçeği tekniği kullanılarak anketler hazırlanmiştır.

Toplanan veriler, korelasyon ve regresyon temelli yol analizlerine tabi tutularak hipotezler test edilmiştir. Analiz sonuçlarına göre örgütsel sıkılık-esneklik ile sosyal kaytarma ve yenilikçilik arasında anlamlı ve negatif yönlü ilişkiler tespit edilmiştir. Örgütlerdeki sıkılık algısı arttıkça kaytarma davranışı azalırken, esneklik algısı arttıkça da yenilikçilik davranışı artmaktadır. Bu bulgular tartsş1larak yönetici ve uygulayıcılara çeşitli önerilerde bulunulmuştur.

Anahtar Kelimeler: Örgütsel Sıkılık-Esneklik, Sosyal Kaytarma, Yenilikçilik

\section{The Effects of Organizational Tightness-Looseness on Social Loafing and Innovation: A Research on Academicians}

\begin{abstract}
In today's competitive world, organizations must also closely monitor changes in socio-cultural areas in order to survive and gain competitive advantage. At the same time, organizations should be able to adapt their strategies to changes. The way individuals in different societies, different organizations or even different groups perceive events is also different. One of the cornerstones of this difference is the cultural structure. The perception of firmness-flexibility, which is a cultural dimension discussed in this study, can also affect many behavioral outcomes of employees. Individuals working within the organization may develop a number of attitudes and behaviors as a result of working with others. Social slacking tends to be one of them. If necessary, the perceived cultural structure of the organizations should be established in such a way as to prevent this slacking behavior, to reveal the actual capacity of the individuals and to use it for the benefit of the organization. At the same time, this cultural perception will be able to frame individuals and organizations ' tendency to act innovatively. Employees will be able to act more innovatively in structures where people can participate in decisions, where creativity is supported and rewarded.
\end{abstract}

\footnotetext{
*Dr., Millî Savunma Bakanlığı, arzuugurlukara@outlook.com

** Doç. Dr., Milli Savunma Üniversitesi, mbegenirbas@kho.edu.tr

Makalenin Gönderim Tarihi: 06.05.2020; Makalenin Kabul Tarihi: 31.10.2020
} 
Structures that closely follow scientific and technological innovation, take risks, adapt to changing environmental conditions will be more likely to succeed. It is evaluated that the innovations that higher education institutions will make in producing and sharing information and their follow-up will make a positive contribution to the educational process. In this case, in light of the cultural structure of their institutions, it will be important for managers at universities to view innovation and support rates, to take risks, to include everyone in this process, expecting equal dedication and work discipline from everyone. In this study, it was investigated how the perceptions of tight and flexible organizational culture in academicians ' institutions affect their innovative behavior and possible tendency to slip out of unity.

The research was carried out by the analysis of the datas collected via sample method from 236 academicians who work in some universities which are located in Ankara province. A 6-question scale developed by Gelfand et al (2006) and adapted by Özeren (2011) to measure the perception of tightness-flexibility, a scale of 4 questions, adapted from the work of Mulvey and Howard (1998) and George (1992), translated into Turkish by Şeshen and Kahraman (2014), to measure the perception of social slacking, Developed by (Jong, 2007) to measure the trend of innovation, Köksal et al. (2018) used a scale of 10 Questions adapted into Turkish. Questionnaires using the 5-point Likert scale technique, which corresponds to the values of "absolutely disagree" (1), "disagree" (2), "undecided" (3), "agree" (4) and "strongly agree" (5) it was prepared.

The data collected were subjected to correlation and regression based pathway analyses and the hypotheses were tested. According to the results of the analysis, meaningful and negative relations between organizational tightness-looseness and social loafing and innovation were determined. As the perception of tightness increases in organizations, loafing behavior decreases, while as the perception of looseness increases, innovation behavior increases. These findings were discussed and various suggestions were made to managers and practitioners.

Keywords: Organizational Tightness-Looseness, Social Loafing, Innovation

\section{Giriş}

Gerek toplumların gerekse toplumlarda varlığını sürdüren örgütlerin, sahip oldukları farklı kültürel yapılar göz önünde bulundurulduğunda, durum ve olaylara da farklı bakış açıları geliştirmeleri kaçınılmazdır. İşte bu bakış açılarının, yap1 ve stratejilerin kurulmasındaki önemleri yadsınamaz. Bu stratejiler sayesinde örgütler, değişen dünya koşullarına ayak uydurmada, çalışanlarının gerçek kapasitelerini ortaya çıkarma ve kullanmada artı konuma geçebilirler. Tabi burada stratejileri hayata geçirirken dikkat edilmesi gereken hususlardan bir tanesi de sahip olunan kültürel yapıdır.

Alan yazına bakıldığında örgüt kültürü genel olarak; örgüt içerisinde oluşan değer, inanç, tutum ve normların sonraki nesillere aktarılması ile çalışanları bir arada tutan olgudur (Kilmann, vd., 1985). Çalışanlann bir arada tutulması için de ortak kabul görmüş kurallara uyma eğilimi, uymayanlara karşı geliştirilen tepkiler ve uygulanan yaptırımların derecesi, o örgütün ne kadar sıkı veya ne kadar esnek bir kültüre sahip olduğu hakkında ipucu verecektir. Gelfand ve arkadaşları (2006, s. 1225), sık1lık-esnekliği normların geçerliliği ve yaptırım gücü olarak tanımlamışlardır. Yani bir toplulukta normlar ne kadar etkili ve kapsayıcı ise o topluluk daha sıkı olarak adlandırılır. Bu normların çok etkileyici olmadığı, sapmaların hoşgörü ile karşılandığı topluluklar ise daha esnek kültüre sahip topluluklardır.

Öte yandan örgüt içerisindeki kültürel yapıya uyup/uymamaya karşı verilen tepkiler örgüt içerisindeki bir grup çalışan tarafindan geliştirilmektedir. İşlerin işleyişinde aktif rol alan çalışanlar, grupları dolayısıyla örgütün başarısını önemli ölçüde etkilemektedir. Bu çalışanlanın ve grupların sayısı işin verimliliğini de değiştirecektir. Grup içerisinde diğerleriyle birlikte çalışmak, kapasite ve başarıyı en üst düzeye çıkaracağ1 gibi herkesin gerçek kapasitesini kullanmayarak başarı düzeyini düşürebileceği de bazı çalışmalarla ortaya konmuştur (Karau ve Williams, 1997, s. 156-168). Yani kişiler grup içerisinde çalışırken nasıl olsa diğerleri çalışıyor düşüncesi ile gerçek çabasını göstermekten kaçınabilir. Bu durum literatürde sosyal kaytarma algısı veya davranışı olarak yerini almıştır.

Ayrıca, örgütler açısından içinde bulunduğumuz çağın özeti olarak "gelişen ve değişen teknoloji ve insan gücü ile rekabette üstünlük sağlama ve bunu devam ettirebilme, çok büyük öneme sahiptir”, denilebilir. Gerektiğinde değişim hususunda en küçük bir ayrıntının bile örgütü başarılı/başarısız kılacağı unutulmamalıdır. Çünkü büyük olmanın en güzel yanlarından biri de küçük parçaları düşünebilmektir. Dünya, insanların her şeyi aynı anda öğrendikleri büyük bir köy halindeyse, bir örgütün takip ettiği bir yeniliğin rakipleri tarafından da hız kaybetmeden öğrenileceği unutulmamalı, bir başka yeniliğe de ekipman olarak hazır bulunulmalıdır. Bu ekipmanlardan belki de en önemlisi çalışanların yenilikçi fikirleri ve davranışlarıdır. Gerekli olan, bu değişimlere ayak uydurabilmek, bunu yaparken değişimi kendi kültürümüzle yoğurabilmek ve tüm çalışanları eksiksiz bu değişim sürecine katabilmektir. Çünkü yaşanan bütün değişimlerden bireylerin ve örgütün performansı etkilenecektir. Dünya çapında ülkelerin inovasyon performanslarını yansıtan önemli raporlardan bir tanesi de "Küresel İnovasyon Endeksi (KİE)"dir. 
KİE’nin 2019 verilerine göre, Türkiye 126 ülke arasında son altı yılda 50. siradayken 2019 yllinda inovasyon girdi ve çıkt alt endeksleri kategorilerinde 49. sıraya yükselmiştir. Puan kaybedilen bir alt indeks de bilgi ve teknolojideki inovasyon kategorisidir. Burada buluşlar, patentler, bilimsel yayın sayıları gibi ölçütlere bakılmıştır (2019 Yılı İnovasyon Endeksi). Ülkeler açısından önemli olan, yenilik yapabilme kapasitelerini arttırarak rekabette üst sıralarda yer almalarıdır.

Örneklem olarak ele alınan akademisyenlerin yenilikçi ve kaytarma davranış eğilimlerini tespit etmek, bu davranış kalıplarının nasıl bir örgüt kültüründe daha rahat ortaya çıktığını ve olumsuz durumlarda ne gibi önlemler alınabileceğini kestirebilmek adına çalışmanın yazına katkı sağlayacağı değerlendirilmektedir. Çünkü, akademisyenler bilgiye hizmet etmekte, günümüzde de bilgi hızla değişmekte ve yayılmaktadır. Dolayısıyla akademisyenlerin bu değişimlere uyum sağlayabilmesi, şu anın ve geleceğin ihtiyaçlarını karşılayacak bireyleri yetiştirebilmesi için çalıştıkları kurumların buna uygun ortamı yaratması gerekmektedir. Akademisyenler bu anlamda bireyleri üniversiteden topluma doğru kazandırarak katalizör görevini de üstlenmişlerdir. Örneğin günümüzde mücadele edilen Covid-19 salgını kapsamında, üniversiteler uzaktan eğitimle öğrencilerine ulaşmaya çalışmakta ve ekran üzerinde öğrenmeyi gerçekleştirmeye uğraşmaktadır. Bu süreç boyunca akademisyenlerin teknolojiyle eğitimi entegre etmeleri, bu yeni düzene hızla adapte olmalanı, bunu yaparken esnek çalışma düzeninden ötürü çalışma disiplinlerinden vazgeçmemeleri beklenir. Yükseköğretim kurumları çevresel dönüşümler ve değişimler içerisinde kendi iç çevresini de buna uyum sağlamaya yönlendirmelidir. Kendi yenilikçi davranışlarını oluştururken çevresel değişimlerden etkilenmemesi de pek mümkün değildir. Bir örgütün sıkı veya esnek olması da bu durumu etkileyen iç çevre faktörlerindendir.

S1kılık-esneklik kültür boyutunun sadece toplumsal değil aynı zamanda örgütsel bazı çıktıları da etkileyebileceğinin araştırlması gerektiği (Gelfand vd., 2006, s. 2011) çağrısından yola çıkılarak, bu kavramın örgütsel düzeyde yenilikçilik ve sosyal kaytarma ile olan ilişkileri belirlenmeye çalışılmıstır. Ulusal yazında, bahse konu olan değişkenlerin bütün olarak ele alındığı başka bir araştırma bulunmadığından, literatüre katkı sağlayacağı gibi yönetici ve uygulayıcıların da yönetimsel davranışlarında değişikliklere yol açacağ1 değerlendirilmektedir. Bu çalışmada araştırma ve yayın etiğine uyarak, öncelikle kavramsal tanımlamalara ve teorik ilişkilere yer verilmiş, daha sonra da hipotezler geliştirilerek test edilmiş ve analiz sonuçları raporlanarak yorumlanmıştur.

\section{Kavramsal Çerçeve}

\section{1. Örgütsel S1kılık-Esneklik}

Literatürde kültürle ilgili çalışmaların gün geçtikçe arttığı görülmektedir. Bunun sebeplerinden bir tanesi de oluşturulmuş bir kültürel yapının kaos ve karmaşıklı̆̆ en az düzeye indirmesi olarak söylenebilir. Örneğin, bir örgütün kültürel yapısından kaynaklı yazılı olmayan bazı kuralları olsa da örgüt üyeleri o kurallara kendilerini uymak zorunda hissedecektir. Ancak bu örgütten örgüte değişecektir. Kimi örgüt kural ve normlara uymanın çok üzerinde dururken, bir diğeri bu kadar sert kurallara sahip olmayabilir.

İşte burada, literatürde yeni yeni çalşsılmaya başlanmış, kural ve normlara uyma derecelerine göre sınıflandırılmış "kültürel sıkılık-esneklik" kavramı devreye girmektedir. S1kılık-esnekliğin temelde iki bileşenden oluştuğu söylenebilir ve konunun daha iyi anlaşılması için iki bileşenin açıklanmasında fayda vardır. Bunlardan birincisi; toplum veya örgüt içerisinde kuralların ne kadar anlaşılabilir ve yaygın olduğu ile ilgilidir. İkincisi ise bu kurallardan sapmalara gösterilen hoşgörü düzeyidir (Wasti \& Fiş, 2010, s. 12).

İlk kez Pelto (1968, s. 37-40) tarafindan sıkılık ve esneklik kavramına değinilmiş, sıkı ve esnek toplumlar arasındaki farklar irdelenmiş, toplumlann kendilerini nasıl ifade ettikleri ve sosyal normlara ne kadar bağlı olduklarına dair araştırmalar yapılmıştır. Örneğin, Pelto (1968, s. 37-40) normların çok katı ve kesin olduğu, bu normlardan sapmalara ağır cezaların verildiği Japonya'yı sıkı bir toplum olarak değerlendirirken, norm ve kuralların çok katı olmadığı, gerektiğinde esnetilebildiği ve bunlardan sapmalara hoşgörü ile yaklaşıldığı Finlandiya'yı esnek toplum olarak değerlendirmiştir. Eski tarihte hayatlarını tarımclıkla idame ettirmeye çalışan toplumlar sıkı toplum olarak kabul edilmekteyken, avcılık ve balıkçılıkla uğraşan toplumlar nispeten daha esnek toplumlar olarak değerlendirilmiştir. Aslında konu hakkında yapılan araştırmalara bakıldığında bir toplumu sıkı veya esnek olarak ayırt edebilmek için onların yaşam mücadelesine bakılması gerektiği, çünkü toplumların buna uygun kural ve norm geliştirdiği görülmektedir 
(Pelto 1968, s. 37-40; Gelfand, Nishii \& Raver, 2007, s. 1-59; Triandis, 1989, s. 506-520; Gelfand vd., 2010, s. 14). Ayrıca Chan ve arkadaşları (1996), Carpender (2000), Wasti ve Fiss (2010) de sıkıllk-esneklik ile ilgili çalışmalara temel teşkil edebilecek bilgileri araştırmaları ile ortaya koymuşlardır. Gelfand ve arkadaşları (2011) örgütsel sıkılık-esneklik ile ilgili 33 toplum üzerinde ilk kapsamlı araştırmayı gerçekleştirmişlerdir. $\mathrm{Bu}$ araştırma sonuçlarnna bakıldığında sıkılık sıralamasına göre Türkiye 9,2 puan skoruyla yedinci sırada yerini almıştır. Bu araştırma 7239 katılımcı üzerinde yapılmış ve sıkılık-esneklik açısından ülkeler arasında anlamlı farklar olduğu görülmüştür.

Konuya örgütsel açıdan bakılırsa çalışanların örgüt yapılarını nasıl algılladığı ile ilgili durumun önemli olduğu görülmektedir. Örgütlerin de aynen toplumlar gibi kendilerine özgü kültür yapıları vardır. Çalışanlar, bu farklı kültür yapıları içerisinde farklı sonuçlar üretmektedir (Senge, 2004, s. 34; Johnson, 1998, s.145). Bir örgütün kültürel yapısı, o örgütün dış çevredeki elde edeceği güç üzerinde de çok etkilidir (Aydıntan \& Göksel, 2012, s. 54). Bu sebeple örgüt kültürü iyi tanımlanır ve çalışanlara doğru aktarılırsa arzulanan hedeflere daha rahat ulaşılabileceği düşünülmektedir.

$\mathrm{Bu}$ çalışmada eğitim kurumlarının kültür yapısının sıkı veya esnek olması algısının akademisyenler üzerindeki etkileri incelenmiştir. Bakıldığında sıkı örgüt kültürüne sahip eğitim kurumlarında, kurallar daha etkilidir, eğiticiler itaat bekler, eğitilenler de izlendiklerini bildikleri için diğerleri gibi davranmaya çalışırlar (Holzer, 2000, s. 72; Chen, 2000, s. 230). Burada eğitim kurumlarının büyüklüğ̈̈ de kültürel yapıyı etkileyen önemli bir faktördür. Çünkü, büyük ölçekli kurumlarda yani çalışan sayısının fazla olduğu yapılarda kalabalıklığın vereceği kaos ve karmaşıklığın önüne geçmek için sınırların net olması gerekir, bu da sı1k bir örgüt kültürünün var olmasına işaret eder. Nüfus yoğunluğu düştükçe kültürel yapı biraz daha esneyebilir (Chan vd., 1996, s. 4). Fazla nüfustan kaynaklı verimli ve doğru bir performans değerlendirmesi yapılamazsa kaytarma davranışları gözlemlenebilir, bu tarz problemlerin önüne geçmek için de sert yaptırımlar uygulanması kaçınılmaz olur. Bu sebeple sıkı kültürlerde ceza gerektiren davranışların yelpazesi geniştir, sosyal baskı fazlaca hissedilir. Ayrıca bu kültüre sahip örgütlerde yüksek merkezileşme ile beraber bilgi akışı yavaşlayabilir, değişime anında cevap verilemeyebilir. Eğitim kurumlarından beklenti bu yönde olmadığından akademisyenlerinde oluşacak kültürel yapı algısını yönetebilmek ve yönlendirebilmek gerekir. Böylesi hem yenilik ve değişimin hem de düzenin istendiği kurumlarda, özdenetim ve sorumluluk almanın önemi büyüktür.

Kuralların, normların ve bundan sapmalara uygulanan yaptırımların az olduğu esnek topluluklarda sosyalizasyon daha çoktur. Farklilkkların ön planda olduğu, sapmalara toleranslı davranıldığ1 bu topluluklarda kişiler hesap verme zorunluluğu duymamakta, başarmaya daha çok odaklanmakta, girişimci olarak risk üstlenmeye isteklidirler. Dolayısıyla değişime sıcak bakılmakta ve hatta zorunluluk olmaktadır. Örgütün kültürü ve yapısı, örgütü yeniliklere ve değişimlere teşvik edebilecekken tam tersi durağanlığa da yönlendirebilir. Örgüt içerisinde çalışan bireyler açısından düşünülürse hissedilen hesap verme zorunluluğu, kişileri ya yeniliğe ya da durağanlığa sürükleyecektir (Gelfand vd., 2006, s. 7). Hesap verilebilirlik, riskten kaçınma, girişimcilik yönelimi, denetim, gruba uyum, merkeziyet, örgüt içi yazılı kurallar gibi nüanslar bir örgütün sık1 veya esnek olması hakkında bize fikir verecektir. O halde geleneksel örgüt yapılarında sıkı kültür boyutunun, yenilikçi örgüt yapılarında ise esnek kültür boyutunun baskın olmas1 beklenebilir.

\subsection{Sosyal Kaytarma}

Bakıldığında bir evin içerisinde bile aile üyelerinin birbirlerinin davranışlarını şekillendirmesi çok olağan bir durumdur. Bunu büyük ölçekli düşündüğümüzde bir örgüt içerisinde çalışanlar birbirlerinin davranışlarına çok rahatlıkla yön verebilir ve bu durum verimliliği olumlu/olumsuz etkileyebilir.

Alan yazında grup çalısmaları ile ilgili pek çok araştırma yapıldı̆̆ı görülmektedir. Bu araştırma konularından bir tanesi de sosyal kaytarma eğilimi ile ilgilidir. İş bölümü yaparak grupsal çalışma düzeninde çalışılmasının hem avantajları hem de dezavantajları olabilmektedir. Örneğin Ringelmann (1913), dinamometreye bağlı bir ipin çekilmesi ile ilgili bir test yapmıştır. Bu test sonucunda grubun üye sayısının artıkça, her bir bireyin uyguladığı kuvvetin azaldığı, eşgüdüm ve motivasyon kaybı yaşandığı görülmüştür (Hogg \& Vaughan, 2011, s. 315). Buna benzer testler başka araşturmacılar tarafindan da yapılmış ve bu motivasyon kaybı literatürde 'sosyal kaytarma' kavramı olarak yerini almışır. Örneğin, Ingham, Levinger, 
Graves ve Peckham (1974, s. 372; akt. Hogg \& Vaughan, 2005, s. 310) tarafindan yapilan halat çekme deneyinde ve Latane, Williams ve Harkins (1979, s. 825) tarafindan yapılan el çırpma ve bağırma deneylerinde kişinin yalnızken ve grup içerisindeyken gösterdikleri performanslanı ölçülmüss, sonucunda kişinin tek başına gösterdiği performansın, grup içerisindeyken gösterdiği performanstan daha yüksek olduğu görülmüştür.

Bireylerin, yalnızken çalışmalarına kıyasla grup içerisinde bir işi yaparken nasıl olsa diğerleri çalş̧yor düşüncesi ile kendi gerçek performanslarını göstermekten kaçınmalarına sosyal kaytarma denir (Williams, vd., 1993, s. 131). Bazen içinde çalıştığımız grubu seçemeyiz. Bu durumda kişiler ya az çalışanların yarattığ1 boşluğu doldurmaya çalışırken beklenilenden daha fazla çaba harcar, ya da diğerleri gibi daha az çalışma gayreti içine girerler. Yöneticilerin grup içinde de olsa bireysel bazda beklenilen performans düzeyini çalşanına iletmesi ile bu gibi olumsuz durumların önüne geçilebilmesi, onların yönetim tarzları ve çalışanlanına davranışlarıyla da orantılı olarak değişebilecektir.

Eğitim kurumları ele alındığında eğiticilerin hem öğrencilere hem de idareye karşı birtakım sorumluluklanı vardır. Eğiticilerden, resmi olarak veya kendiliğinden oluşan görevleri yerine getirirken görevlerini aksatmadan, eksiksiz çalışmaları beklenir. Çünkü herhangi bir olumsuzlukta birçok çevresel faktör bundan etkilenebilir. Ertürk ve Argon'a (2019) göre, bu olumsuzluklar kişinin kendisinden, çalşsma ortamından veya yöneticilerinden kaynaklanabilir. Örneğin, bu olumsuzluklardan bir tanesi de kaytarma davranışlanıdır. Eğiticilerin çalışıklan kuruma karşı aidiyet hissetmemesi, yaptığı işi sevmemesi, ders ve iş yükünden kaynaklı yorgunluk, diğerleri tarafindan kullanıldı̆̆ını düşünmesi gibi faktörler kaytarma davranışını tetikleyebilir (Kilıçarslan, 2018). Maalesef bu kaytarma davranışlanı, en başta eğitim sürecini, öğrencileri, diğer eğiticileri ve kurumun tamamını başarısızlı̆g uğratabilecektir. Çünkü sosyal kaytarma acilen önlem alınması gereken, gizlice yayılan tehlikeli bir durumdur (Balc1, 2017, s. 373).

Literatüre bakıldığında sosyal kaytarma davranışı, işi ‘eksik' veya 'kötü’ yaparak kendini gösterebilir. Yani kişilerin ya işi yapacak bilgi ve becerileri yoktur ya da dikkatini işine yoğunlaştırmaz ve bozuk davranışlar sergiler. Her ikisi de üretkenlik ve verimliliği olumsuz etkilediği için kaytarma davranışı olarak kabul edilebilir (Nicholson, 2012). Bir örgütteki her bir çalışan sorumluluklarını tam anlamıla yerine getirme gayreti içinde olursa hem kendi hem de diğerlerinin kaytarmasının önüne geçebilir. Erarslan (2011, s. 82), hiçbir çıkar gözetmeden, isteyerek çalışan kişilerin görev bilinçlerinin ve bireysel sorumluluklarının yüksek olduğunu söylemektedir. Zaten kişinin bireysel sorumluluk anlayışı gelişmişse diğerlerinin de ihtiyaçlarını dikkate alarak çalışma değerleri benimseyecektir (Çankaya, 2010, s. 378). Çünkü, sorumluluk düzeyleri ve öz disiplinleri gelişmiş kişiler, hırslı, başanı odaklı, uyumlu iken, bu nitelikleri düşük olan kişiler ise görev bilinci kazanamamış, iş disiplinleri ve prensipleri olmayan, işlerini devamlı erteleyen veya başkasına yaptıran kişilerdir (Jensen-Campbell \& Malcolm, 2007, s. 370; Bacanlı vd., 2009, s. 262).

Örgütün sahip olduğu kültür yapısı da sosyal kaytarma üzerinde etkilidir, çünkü kültür aynı zamanda değer yargılarını da belirler. Bu değer yargılarına istinaden birey diğer çalışanlara karşı kaytarma davranışının hoş karşılanmayacağını bilir. Tsaw ve arkadaşlanı (2011, s. 2), bir grup içerisindeki kültürel farklılıkların çalışma motivasyonunu azalttığını ortaya koyan çalışmalar yapmışlardır. Literatürde, sıkıııkesneklik boyutunun bireycilik-çoğulculuk boyutlarıyla benzeştiğini, bireyciliğin esnek kültür yapısına daha yakınken, çoğulculuğun sıkı kültür yapısına daha yakın olduğunu ortaya koyan çalısmalar mevcuttur (Carpender, 2000; Chan, vd., 1996; Triandis, 1989). Amerikan ve Çin şirketlerinde yapılan bir araştırmada, bireyselliğin önemli olduğu Amerika'da sosyal kaytarma fazla iken, çoğulculuğa önem veren Çin'de sosyal kaytarma yok denecek kadar az çıkmıstır (Earley, 1993, s. 319-348). Sık1 ve esnek örgüt yapılarının sosyal kaytarmayı nasıl etkilediğine dair bir araştırma da Uğurlu Kara (2020) tarafindan akademisyenler üzerinde yapılmış ve sonucunda örgütsel sıkılık ile sosyal kaytarma arasında negatif yönlü anlamlı ilişkiler tespit edilmiştir. Bu çalışmada örgüt kültürü algısının kaytarma davranışı üzerindeki etkisine binaen yöneticiler tarafından gerekli önlemler alınabileceği değerlendirilmektedir.

\subsection{Yenilikçilik}

Yenilik her ne kadar sıfırdan oluşturulup ortaya atılmışş şeyler olarak algılansa da çoğu zaman hazır olan hususların farklı sunumlarıla da vücut bulmaktadır. İster yeni olsun ister yenilik katılmıs olsun önemli olan her iki durumun da değer yaratmasıdır. Bu yaratılan ekonomik veya sosyal değerler sayesinde örgütlerin 
maddi-manevi kazanımlar elde edeceği değerlendirilmektedir. Bu değerler kazanılmaya çalışılırken akla sadece örgütün gerçekleştirdiği faaliyetler değil aynı zamanda bunun ötesinde kültürel olarak içselleştirilmiş bir değişim ve gelişim süreci de gelmelidir.

Yenilikçilik, ürün, hizmet, strateji, süreç, personel bazında yapılabilir (Mehta, 2006). Literatürde yenilikçiliğin farklı boyutlarda ele alındığı çalışmalar mevcuttur. Bu çalışmada daha çok yenilikçi davranışları ile konu irdelenecektir. Yenilikçi davranış, bir örgüt içerisinde yeni düşüncelerin üretilmesinin desteklenmesi ve uygulanabilirliğinin arttırllması olarak ifade edilebilir (Yuan ve Woodman, 2010). Örgüt içinde yeniliğin verimli uygulanabilmesi personelin de bu uygulamalan desteklemesi ile artacakttr.

Yenilik, başarıya ulaşabilmek için yeni çözüm yollarının geliştirilmesi, yeni ürün ve süreçlerin oluşturulması ile yeni teknolojiyi üretmek veya takip etmek olarak tanımlanabilir (Liu, vd., 2002, s. 370). Yenilik sürecinde insan kaynakları, üretim, pazarlama, satış ve teknoloji kritik bir öneme sahiptir (Burgelman vd., 1996). İssletmelerin dünya genelindeki yenilik sürecine anında dahil olabilmeleri bu konulardaki gerekli altyapılarının yeterli ve hazır olmasına bağlıdır. Giriş bölümünde bahsedildiği üzere Covid-19 sürecinde üniversiteler, yapılarını bu salgın sürecine adapte etmeye çalışırken hem eğiticilerin hem de eğitilenlerin bu sürece adapte olması konusunda yeni süreçler tasarlamaktadır. Zor olduğu kadar uzun süren olan bu salgına karşı yeniliğe kapalı olan sıkı örgüt kültürüne sahip üniversiteler bile hızlıca uyum göstermek durumunda kaldıkları görülmektedir.

Bu da demek oluyor ki yenilik sürecinde etkili olan önemli konulardan bir tanesi de "kültürel çevre"dir (Yeşil, 2012, s. 39). Yaratıcılık ve yenilik ancak belirli kültürel ortamlarda ortaya çıabilmektedir (Westwood ve Low, 2003, s. 9). Sosyo-kültürel ve ekonomik-politik alandaki yenilik hedeflerine ulaşmada kültürün gücüne gereksinim vardır (Bedük vd., 2003, s. 28). Bir örgütün kültürel çevresi, çalışanların davranış ve tutumlarına yön verdiğinden, örgüt içerisinde yenilikçiliği teşvik etme veya engelleme gücüne sahiptir. Elenkov ve Manev (2009, s. 357) çalışmalarında, kültürün örgütsel yenilik sürecinde etkili olduğunu ortaya koymuşlardır. Yenilikçilik aslında başlı başlına bir kültür alt boyutu olarak literatüre kazandırılmıştır (Wallach, 1983, s. 33). Bu nedenle örgüt kültürü eşzamanlı yenilikçi kültüre de sahipse rekabet anlamında başarısı artacaktır (Zhang \& Lie, 2012, s. 702). Bu başarıda örgütün etkinliğinin ve kapasitesinin arttırılması, bunun kalıcı olması yenilikçilikteki başarıya bağlıdır (Wang ve Ahmed, 2004, s. 303). Yenilikçiliği destekleyen örgütlerin özelliklerinde desteklemeyenlere kıyasla olumlu yönde büyük farklılıklar vardır. Bu farklılı̆̆n yarattı̆̆1 değerlere sahip olmak, o örgütü rekabette başarıya götürecek bir yol haritasi olabilir (Dobni, 2006, s. 329-335).

Esnek kültürlerde risk alma, yenilikçilik, daha az merkeziyetçilik, hoşgörü, katılımcılık gibi özelliklerin ön plana çıktığından yukarıda bahsedilmişti. Yenilikçilikte de risk alma, belirsizlik, değişim, tolerans gibi özellikler vardır. Dolayısıyla, yenilikçi davranış ancak onu destekleyen bir örgüt kültürü içerisinde ortaya çıkabilmektedir (Luecke, 2011, s. 142-144). Böylece, esnek olup değişime direnç göstermeyen bir örgüt yaratıcllı̆̆ da teşvik etmiş olacakttr (Judge, 1997, s. 73). Öte yandan, değişimi destekleme ile eğitim ve gelişimi sağlama, sürekli öğrenmeye hazır ortam oluşturma, yeni fikirler oluşturma ve paylaşma ile (Jucevicius, 2007) hem yenilikçilik desteklenmiş hem de bireysel iş performansı arttırılmış olacaktır (Chen vd., 2003, s. 1013). Üniversiteler bu gereksinimleri karşılayacak bireyleri topluma kazandıran arac1 kuruluşlardır. Akademisyenlerin bunu sağlaması için de örgütlerinde esneklik hissetmesi, özgür karar verebilme iradesine sahip olabilmesi önemlidir.

Bakıldığında sık1 örgütlerde normlardan sapmalara hoşgörü ile bakılmadığından ve hatta yaptırım uygulandığından bu kültürlerde birçok alanda benzerliğin görülmesi de kaçınılmazdır. Eğitim veren kurumlarda da durum böyledir, yani sıkı kültüre sahip olan eğitim kurumlarının benzer eğitim süreçlerine sahip olduğu görülebilir. Yamamato $(2020$, s. 45) çalş̧masında, bu durumun bireysel ve toplumsal gelişimin önüne geçebileceğini söylemektedir. Bu sebeple günümüzde birçok üniversite girişimci ve yenilikçi yapılara yönelmişlerdir. Örgütler yenilikçi, her duruma hızla adapte olup başarabilen çalışanlar istiyorsa bunun temeli eğitim kurumlarında atılmaya başlanmalıdır. Akademisyenlerin öğretme sürecinde farklı yöntem ve teknolojilerden faydalanması kalıcllı̆ı arttıracaktır. Bunu yapabilmesi için de kurumu tarafından desteklenmesi gerekmektedir.

Yenilikçilik süreci fikir ve düşüncelerin üretilmesi aşaması ile bunların benimsenmesi aşamasından oluşur (Kaasa \& Vadi, 2008). Desouza ve arkadaşlarına (2009, s. 10) göre de bu aşamalar, fikir ve 
düşüncelerin oluşturulması, en iyisinin seçilmesi, denenmesi, ticarileştirilmesi ve yayılması aşamalarından oluşur. Ceylan'a (2013, s. 45) göre de fikir üretimi ile orijinal fikirler ortaya konur, fikir tanıtımı ile çevredeki kişiler fikirden haberdar edilir ve fikrin desteklenmesi sağlanır, fikrin uygulanması ile de geliştirilen model uygulamaya girer ve değerlendirmesi yapılarak yenilikçilik süreci tamamlanır. Jong (2007), yenilikçilik sürecini firsat geliştirme, fikir üretme, fikri savunma ve fikri uygulama aşamaları ile ele almış ve bu çalışmada da yenilikçilik bu boyutlanı ile araştırılmıştır.

\section{4. Örgütsel Sıkılık-Esneklik, Sosyal Kaytarma ve Yenilikçilik Arasındaki İlişki}

Örgüt kültürü çevresel birçok şeyden etkilendiği gibi kendisi de birçok şeyi etkilemektedir. Bu araştırma örneklemi açısından kendine özgü kültürel yapıları olan üniversitelerdeki akademisyenler üzerinde yapılmıştır. Akademisyenlerin örgütlerine ait sık1 veya esnek kültür algılanı, onların sosyal kaytarma eğilimlerini ve yenilikçi tutumlanını nasıl etkilediği sorusunun cevabı ile literatüre katkı yapılmaya çalışılmıştır.

Bir çalışma grubu içerisinde bireyler nasıl olsa kimse fark etmiyor veya fark edilse de bir yaptırım uygulanmıyor, daha fazla çalışsam da elde ettiğim kazanım değişmiyor gibi düşüncelerle kaytarma eğiliminde bulunabilirler. Bu yüzden, çalışmaya başlarken sıkı kültüre sahip örgütlerde hesap verilebilirliğin çok olması denetim ve yaptııım mekanizmalarının sürekli işlemesi ile çalışanların kaytarma davranışında daha az bulunacakları düşünülmüştür. Kültürel sıkılığa sahip örgütlerde kural ve normlar açık ve kesindir, herkesin de bu kurallara uyması beklenir, iş görenler hesap verilebilirlik ilkesi çerçevesinde işlerine devam ederler. Kültürel esnekliğe sahip örgütlerde ise kural ve normlar yumuşatılabilir ve duruma göre değişebilir, sapmalara hoşgörü ile yaklaşlır, iş görenler de bu rahatlıkta işlerine devam ederler. Çalışanların bu iki boyuta dair örgüt kültürlerini nasıl algıladıkları da onları kaytarma davranışına sevk edebileceği veya bu davranıştan alıkoyabileceği değerlendirilmektedir. Ayrıca esnek örgütlerde yetkilendirme ve inisiyatif alabilme daha yaygın olduğundan kabul edilebilir davranış aralığ daha geniştir (Gelfand, vd., 2006, s. 12261228; Wasti \& Fiş, 2010, s. 13). Bundan ötürü de çalışanlar gerçek performanslarını göstermekten kaçınabilirler.

Yukanda bahsedildiği üzere Earley (1989), farklı kültürel yapılara sahip olan ülkelerde sosyal kaytarma davranışının görünürlüğünü incelemiş ve sonucunda kültürel yapının sosyal kaytarma üzerinde etkili olduğu sonucuna varmıştr. Bireycilik ve çoğulculuk kültür yapısı, kişilerin sergilemiş olduğu davranışın diğerlerinin davranışlarından nasıl etkilendiği hakkında ipucu vermektedir (Sakal \& Macit, 2018, s. 3353). Hofstede (1993), bu kültürel ayrımdan kaynaklı gruplardaki motivasyon kaybına dikkat çekmiştir. Sosyal kaytarma ve örgüt kültürü ilişkisini araştıran bir diğer çalışma da Sünnetçioğlu ve arkadaşları tarafindan yapılmıştır (2014, s. 3353). Öneren ve diğerleri de (2019, s. 309-318) yüksek öğretim kurumlarında sosyal kaytarma davranışını etkileyen faktörleri ve bunları engellemenin yollarını araştırmışlar ve çalışma sonucunda bireysel özellikler, tükenmişlik düzeyi, örgütsel adalet algisı, örgütsel bağlllık seviyesi gibi faktörlerin kaytarma davranışı üzerinde etkili olduğunu ortaya koymuşlardır. Bu çalışmalardan yola çıkarak literatüre daha fazla katkı yapmak amacıyla, akademisyenlerin kurumlanna dair sıkılık-esneklik algilarının sosyal kaytarma davranışları üzerindeki etkisini ortaya çıkarmak için çalışmanın ilk hipotezi kurulmuştur (H1).

Ayrıca, sık1 ve esnek örgütlerin yeniliğe açık olmaları veya riske girebilme dereceleri de birbirinden farklılık gösterecektir. Bir başka deyişle bu iki kültür, durağanlığa verecekleri tepkinin de farklı olmasıyla birbirinden ayr1lırlar. Kaasa ve Vadi'ye (2008) göre kültür, yenilikçiliğin oluşması için zemin hazırlayabilecekken engel de teşkil edebilir. Herhangi bir durum karşısında, örgütler ya kendi geleneksel kültürlerine bağlı kalacak ya da yeni çözüm önerileri ve teklifler geliştireceklerdir.

S1k1 kültürden gelen bireyler daha gelenekselci olduğu için yeniliğe de dirençli olacaklan düşünülebilir. Örneğin Toh \& Leonardelli (2012, s. 604-611), sıkı kültürlerin değişikliğe daha kapalı olduğundan liderlik rolünü kadınlardan çok erkeklere vermeyi tercih ettiklerini belirtmektedir. S1kı kültürlerde bireyler yaratıc1 çalışmalar yaparken kural ve normlara bağlı kaldıkları için kendilerini daha güvende hissederler (Krauss ve Chiu, 1998, s. 42; Au, 1999, s. 800). Stk1 kültürler normlarnna uygun olmayan yeni fikirleri kavramayabilirler (Toh ve Leonardelli, 2012, s. 605). Çünkü, sıkı kültürlerde istikrar vardır, çevresel değişimler ve yenilikler için yeni normlar geliştirmeye pek sıcak bakmazlar (Chan vd., 1996, s. 5). Esnek kültürler ise daha fazla 
risk alacaklarında yeniliği denemekten kaçınmazlar (Moskowitz, 1993, s. 132). Esnek kültürlerde çalışanlarnn takdir edilmesi de onları yenilikçi olmaya yönlendirecektir. Özeren (2011) araştırmasında sıkılık-esneklik kültür boyutları ile yenilikçilik arasında anlamlı ilişkiler tespit etmiştir. Ayrıca Yeşil (2012) bir çalışmasında yenilikçilik ile kültür arasındaki orantılı niteliksel ilişkiyi araştırmışır. Aynı zamanda Kılınç (2020) yüksek lisans tez araştırmasında üretim sektöründe yer alan firmalardan topladığ1 veriler işı̆̆ında, sıkılık-esnekliğin yenilikçilik üzerindeki etkilerini incelemiş ve sonucunda örgütsel esnekliğin düşük olduğu kültürde yenilikçiliğin de düşük olduğunu ortaya koymuştur. $\mathrm{Bu}$ araştırmalardan yola çıkarak akademisyenlerin, sıkılık-esneklik algılarının yenilikçi davranışları üzerindeki etkisini ortaya koyacak olan ikinci hipotezi kurulmuştur (H2).

Ancak şu da unutulmamalıdır ki, yalnızca bir kültürün (sıkı/esnek) yenilikçi olduğunu veya diğer kültür boyutlarına nazaran her zaman daha yenilikçi olduğunu söylemek doğru olmayacaktır (Westwood \& Low, 2003, s. 253). Yenilikçi davranmada kural ve normlar kültürden kültüre değişecektir (Shane vd., 1995). Bu sebeple, aynı olmayan kültürlerdeki örgütler, yenilikçi yaklaşım açısından içerisinde bulunduğu kültürel yapının gereklerini iyi bilerek buna uygun davranmalıdırlar. Aksi takdirde farklı kültür yapılarında kendi normları ile hareket etmeye çalışmak istenmedik sonuçlar doğurabilir.

Sonuç olarak yukarıda bahsedilen bilgiler ve araşturmalar 1şı̆̆ında bu çalışmada aşağıdaki hipotezler geliştirilmiştir;

Hipotez 1: Örgütsel sıkılık-esneklik akademisyenlerin sosyal kaytarma algılarını etkiler.

Hipotez 1a: Örgütsel sıkılık akademisyenlerin sosyal kaytarma algilarını negatif ve anlamlı olarak etkiler.

Hipotez 1b: Örgütsel esneklik akademisyenlerin sosyal kaytarma algılarını pozitif ve anlamlı olarak etkiler.

Hipotez 2: Örgütsel sıkılık-esneklik akademisyenlerin yenilikçiliklerini etkiler.

Hipotez 2a: Örgütsel sıkılık akademisyenlerin yenilikçiliklerini negatif ve anlamlı olarak etkiler.

Hipotez 2b: Örgütsel esneklik akademisyenlerin yenilikçiliklerini pozitif ve anlamlı olarak etkiler.

\section{Araştırma Modeli ve Yöntem}

Çalıssmada örgütsel sıkılık ve esnekliğin akademisyenlerin sosyal kaytarma algilarına ve yenililikçilik davranışlarına olan etkilerinin ortaya çıkarılması amaçlanmakta ve bu maksada hizmet edecek şekilde Şekil1'de gösterilen biçimde bir model kurularak model üzerinde geliştirilen hipotezlerin gösterimi yapılmıştır.

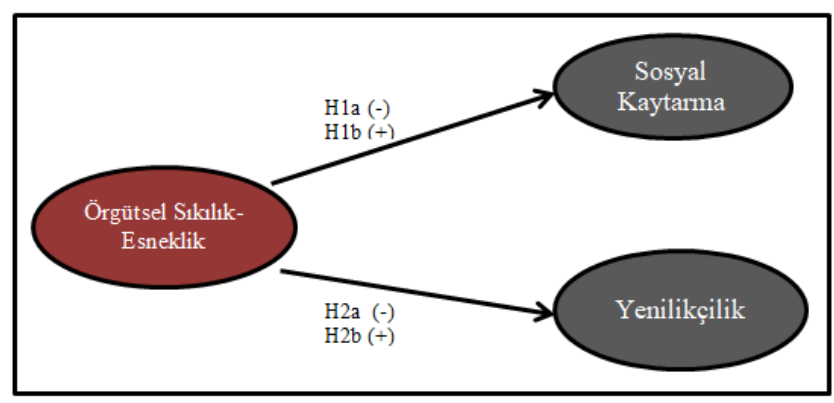

Şekil 1. Çalışmanın Modeli ve Hipotezler

Bu çalşsmada, iki ya da daha fazla değişken arasındaki ilişkilerin herhangi bir şekilde müdahale edilmeden incelendiği korelasyonel araştırma deseninden istifade edilecektir. $\mathrm{Bu}$ araştırmalar neden sonuç ilişkisinin olabileceğine dair araştırmacılara bir fikir vermesi açısından önemlidir (Büyüköztürk, 2007). Katlımcılardan anket formunda yer alan değişkenlere ait alınan veriler, geçerlilik analizi kapsamında yapısal eşitlik modeli kullanılarak (SPSS AMOS 21) doğrulayıcı faktör analizlerine (DFA) tabi tutulacak, güvenilirlik analizleri ile betimleyici istatistikler, değişkenlere ait ortalamalar arasındaki farkllıklar, korelasyon ve regresyon analizleri ise SPSS 21 paket programı kullanılarak yapılacaktır. 


\subsection{Katilimcilar}

Araştırma kapsamına alınan katıllımcı evrenini Ankara'da bulunan toplam 8 kamu üniversitesinde görev yapan akademisyenler oluşturmaktadır. Çalışmada çalışma ve yayın etiğine uyularak, değişkenler arası nedensel ilişkiyi ortaya çıkarabilecek ve araştırmanın teorik alt yapısıyla örtüşecek şekilde kolayda örneklem yöntemiyle 359 akademisyene elektronik ortamda anket formları gönderilmiştir. Ancak söz konusu formların 257'sinde geri dönüş sağlanmıştır. Yapılan ilk değerlendirme ve uç analizleri neticesinde 236 anket formundaki verilerin analizler için uygun olduğu tespit edilerek, çalışma 236 akademisyene ait veriler üzerinden gerçekleştirilmiştir.

Katılımcıların \% 7’sini (15) kadınlar, \% 93'ünü (221) erkekler oluşturmaktadır. Çalışmada kolayda örneklem metodu kullanıldığ için amacımız evrenin tamamını temsil etmekten ziyade o evren içerisinde bulunan kişilere mümkün olduğunca ulaşmaktır. Ayrıca bu çalışma neticesinde elde edilen sonuçlar tüm çalışma evreni için genel sonuç ve öneriler değil, örneklemden elde edilen veriler sonucunda ulaşılan sonuç ve değerlendirmelerdir. Bu nedenle çalışmada basit, tabakalı vb. örneklem metotları kullanılmadığı için cinsiyetler arasındaki bu farkı yukarıdaki açılanan sebepten dolayı bir kısıt olarak görmek gerekir. Yaş aralığına bakıldığında kattlımciların \% 9'u (21) 25 yaş ve daha altı, \% 64’ü (151) 26-35, \%19’u (45) 36-45 yaş aralığında, \%8'i ise (19) ise 46 yaş ve üzerindedir. Medeni halleri kapsamında kattlımcıların \%64'ü (152) evli, \% 36's1 (84) ise bekârdır. Eğitim düzeylerine bakıldığında ise, \% 67'si (158) lisans, \% 26's1 (62) yüksek lisans, \% 7'si (16) ise doktora ve üzeri eğitime sahiptir (Eğitimcilerin yarıdan fazlası henüz yüksek lisans öğrencilerinden oluşmaktadır). Katılımcıların kurumlarında görev yaptıklanı statüleri kapsamında, \%3’ü (7) üst düzey yönetici, \% 22'si (51) orta düzey yönetici, \%14’ü alt düzey yönetici ve \%61'i (146) ise herhangi bir idari ve yöneticilik görevi olmayan akademisyenlerden oluşmaktadır.

\section{2. Ölçekler}

Örgütsel Sıkılık-Esneklik Ölçeği: Çalışmada, sıkılık-esneklik kültür boyutunu ölçmeye yönelik olarak Gelfand ve arkadaşlarının (2006) geliştirdiği ve Özeren'in (2011) Türkçe'ye uyarladığ1 ölçek kullanılmıştır. Ölçek tek boyutludur. 6 maddeden ibaret olup, cevaplar 5'li Likert tipi ölçek kullanılarak alınmıştır $(1=$ Hiç katılmıorum, 5= Tamamen katılıyorum). 5'li Likert'te puanlar 5'e doğru yaklaştıkça örgüte dair sıkılık algisının, 1'e doğru yaklaştıkça ise esneklik algisının arttı̆̆ kabul edilmektedir. Ölçekte yer alan bazı sorular şu şekildedir: "Örgütümüzde çalışanların uymaları beklenen çok sayıda örgütsel norm vardır", "Örgütümüz çalşanları örgütsel normlara hemen hemen her zaman uyar". Söz konusu ölçek daha önceki araşturmalarda kullanıldığı ve Türkçe 'ye uyarlaması yapıldığından sadece Doğrulayıc1 Faktör Analizine (DFA) tabi tutulmuştur. Yapısal Eşitlik Modeli (YEM_AMOS) kullanılarak yapılan tek faktörlü DFA sonucunda ölçeğe ait elde edilen uyum iyiliği değerleri; $\Delta \chi^{2}=8,542, \mathrm{sd}=4, \Delta \chi^{2} / \mathrm{sd}=2,136, \mathrm{RMR}=0,028$, $\mathrm{CFI}=0,989, \mathrm{GFI}=0,988$, AGFI $=0,938$ olarak tespit edilmiştir. Ölçeğin Cronbach Alfa değeri ise 0,831 olarak bulunmuştur. Söz konusu DFA ve güvenilirlik analizi sonuçları kabul edilebilir sınırlar içerisinde ve ölçeğin çalışmada kullanılmasında herhangi bir engel olmadığını göstermektedir.

Sosyal Kaytarma Ölçeği: Sosyal kaytarma algısını ölçmek için Mulvey ve Howard (1998) ile George'nin (1992) çalışmalarından uyarlanan, Şeşen ve Kahraman (2014) tarafindan Türkçe'ye çevrilen ölçek kullanılmıştır. Ölçek 4 soru maddesinde oluşmakta olup tek boyutludur. Sorulardan bazıları; "Çalışıtı̆ım iş yerinde çalışanlar işten kaytarırlar", "Çalıştığım işyerinde çalışanlar yapılan işlere beklediğimden daha az katkı sağlıyor" şeklindedir ve cevaplar 5'li Likert tipinde alınmıştır. Ölçeğe ilişkin tek faktörlü DFA sonucunda elde edilen uyum iyiliği değerleri; $\Delta \chi^{2}=4,302$, sd $=1, \Delta \chi^{2} / \mathrm{sd}=4,302$, $\mathrm{RMR}=0,023, \mathrm{CFI}=0,989, \mathrm{GFI}=0,989$, AGFI $=0,890$ 'dır. Güvenilirlik analizi kapsamında ise, Cronbach alfa değeri 0,845 olarak tespit edilmiştir. Her iki analiz sonuçları kabul edilebilir düzeydedir.

Yenilikçilik Ölçeği: Akademisyenlerin yenilikçi davranışlarını ölçmek için (Jong, 2007) tarafindan geliştirilen, Köksal vd. (2018) tarafindan Türkçeye uyarlanan anket formu kullanılmışır. Ölçeğin orijinal formu 10 madde ve 4 boyuttan oluşmaktadır. Söz konusu boyutlar; firsat geliştirme fikir üretme, fikir savunma ve fikir uygulamadır. Ölçekte bulunan, "İ̧̧lerin nasıl geliştiğini merak ederim", "Sorunlara farklı çözümler geliştiririm", "Önemli örgüt üyelerini yenilikçi fikirler için motive ederim" ve "Yeni işlerin geliştirilmesine çaba harcarım" gibi sorulara katulımcılar tarafından 5'li Liket tipinde (1=Hiç katulmıyorum, $5=$ Tamamen katıllyorum) cevaplar verilmiştir. Ölçeğe ait yapılan birincil seviye (değişkeni alt boyutları 
bazında ele alan) DFA neticesinde elde edilen uyum iyiliği değerleri $\left(\Delta \chi^{2}=247,612, \mathrm{sd}=29, \Delta \chi^{2} / \mathrm{sd}=8,538\right.$, $\mathrm{RMR}=0,041$, CFI $=0,893$, GFI=0,855, AGFI=0,724) kabul edilebilir sınırlar içerisinde bulunmamıştır. Bunun üzerine yapılan ikincil seviye (değişkeni alt boyutları da içerecek şekilde tek boyutlu olarak ele alan) DFA neticesinde uyum iyiliği değerleri kabul edilebilir sınırlar içerisinde $\left(\Delta \chi^{2}=57.325\right.$, sd $=25$, $\left.\Delta \chi^{2} / \mathrm{sd}=2,293, \mathrm{RMR}=0,023, \mathrm{CFI}=0,984, \mathrm{GFI}=0,954, \mathrm{AGFI}=0,899\right)$ tespit edilmiş ve çalışmada yenilikçilik davranışı değişkeni alt boyutları da içerisine alacak şekilde sanki tek boyutluymuş gibi değerlendirilerek, analizler bu kapsamda ele alınmıştr. Ölçeğin güvenilirlik analizi sonucunda Cronbach alfa güvenilirlik katsayis1 0,930'dur.

Çalışmada kullanılan ve yukanda bahsedilen ölçeklere ait DFA neticesinde ulaşılan uyum iyiliği değerleri toplu olarak Tablo-1'de gösterilmektedir.

Tablo 1. Ölçeklere Ait Uyum İyiliği Değerleri

\begin{tabular}{|c|c|c|c|c|c|c|c|}
\hline & $\Delta \chi^{2}$ & sd & $\begin{array}{c}\Delta \chi^{2} / \mathrm{sd} \\
<5\end{array}$ & $\begin{array}{c}\text { RMR } \\
<, 08 \\
\end{array}$ & $\begin{array}{r}\text { CFI } \\
>, 90 \\
\end{array}$ & $\begin{array}{r}\text { GFI } \\
>, 90 \\
\end{array}$ & $\begin{array}{c}\text { AGFI } \\
>, 85\end{array}$ \\
\hline $\begin{array}{l}\text { Örgütsel S1k1l1-Esneklik } \\
\text { (ÖSE) }\end{array}$ & 8.542 & 4 & 2.136 & 0,028 & 0,989 & 0,988 & 0,938 \\
\hline Sosyal Kaytarma (SK) & 4.302 & 1 & 4.302 & 0,023 & 0,989 & 0,989 & 0,890 \\
\hline $\begin{array}{c}\text { Yenilikçilik (Y) } 1 . \\
\text { Düzey }\end{array}$ & 247,612 & 29 & $8,538^{*}$ & 0,041 & $0,893 *$ & 0,855 & $0,724 *$ \\
\hline $\begin{array}{l}\text { Yenilikçilik (Y) } 2 . \\
\text { Düzey }\end{array}$ & 57.325 & 25 & 2,293 & 0,023 & 0,984 & 0,954 & 0,899 \\
\hline
\end{tabular}

\section{Bulgular}

Çalışmada ilk olarak verilere ait ortalamalar, standart sapmalar ile değişkenlerin birbirleri ile olan ilişkilerini ortaya koyan korelasyon düzeylerine bakılmıştır. Analiz neticeleri Tablo-2'de verilmiştir.

Tablo 2. Ortalama, Standart Sapma ve Değişkenler Arası Korelasyon Değerleri

\begin{tabular}{cccccc}
\hline & Ort. & Ss. & ÖSE & SK & Y \\
\hline Örgütsel S1k1lık-Esneklik (ÖSE) & 3,6419 & 0,6119 & $\mathbf{( 0 , 8 3 1 )}$ & & \\
Sosyal Kaytarma (SK) & 2,8404 & 0,8623 & $-0,329^{* *}$ & $\mathbf{( 0 , 8 4 5 )}$ & \\
Yenilikçilik (Y) & 2,9996 & 0,6015 & $-0,326^{* *}$ &,$- 202^{* *}$ & $\mathbf{( 0 . 9 3 0 )}$ \\
\hline
\end{tabular}

${ }^{*} \mathrm{p}<, 005,{ }^{* *} \mathrm{p}<, 001$, Not: Cronbach Alfa güvenirlik katsayıları parantez içinde verilmiştir.

Tablo-2'de görüldüğü üzere, örgütsel s1k1lık-esneklik (ÖSE) ile hem sosyal kaytarma (SK) algis1 hem de yenilikçilik (Y) davranışları arasında orta düzeyde ilişkilerin olduğu (Büyüköztürk, 2008) ancak söz konusu ilişkilerin negatif yönlülük arz ettiği tespit edilmiştir. ÖSE ile akademisyenlerin sosyal kaytarma alg1s1 $(\mathrm{r}=-$ $0,329, \mathrm{p}<0,01)$ ve yenilikçilik davranışları $(\mathrm{r}=-0,326, \mathrm{p}<0,01)$ arasındaki ilişkiler negatif ve anlamlıdır. Akademisyenlerin değişkenlere ait algılarındaki ortalamalar değerlendirildiğinde, sıkılık-esneklik değişkeninin ortalamanın biraz üzerinde olduğu görülmektedir (ort.=3,64). Bu durum akademisyenlerin genel olarak kurumlarını sıkı bir yapıya daha yakın gördüklerini ifade eder. Akademisyenlerin sosyal kaytarma algıları incelendiğinde ortalamada olduğu görülmektedir (ort. $=2,84)$. Bu durum akademisyenlerin kurumlarında yüksek düzeyde kaytarma davranışı olduğunu algılamadıklarını gösterir. Yine akademisyenlerin yenilikçi davranışa dair algılarının orta seviyede olduğu görülmektedir (ort.=2,99). Bu durum akademisyenlerin kurumlarının yenilikçiliğe orta düzeyde açık olduğunu algıladıklarını gösterir.

Ayrıca, demografik değişkenlerin (cinsiyet, yaş, medeni durum, eğitim, statü) diğer değişkenler üzerindeki ortalamaları arasında anlamlı farklara t-testi ve tek yönlü varyans analizi (ANOVA) ile bakılmıştır. Analiz sonuçlarına göre akademisyenlerin değişkenlerin sıkılık-esneklik, sosyal kaytarma ve yenilikçilik davranışlarının çalışmada ele alınan bazı demografik değişkenlere göre anlamlı farklılıklar gösterdiği tespit edilmiştir. Bu kapsamda; erkek akademisyenlerin kadın akademisyenler göre daha yenilikçi davranış sergiledikleri $\left[\mathrm{t}_{(234)}=2,401 ; \mathrm{p}<0,05\right], 25$ yaş ve daha altı olan akademisyenlerin örgütsel sıkılık algılarının puan ortalamasının diğer yaş gruplarına göre daha yüksek olduğu $\left[\mathrm{F}_{(4,235)}=3,793 ; \mathrm{p}<0,01\right]$, evli akademisyenlerin bekâr akademisyenlere göre örgütsel esneklik algılarının daha üst düzeyde olduğu 
[t(234)=-3,907; $\mathrm{p}<0,01]$, eğitim düzeyine göre doktora ve üstü eğitim seviyesine sahip akademisyenlerin yine örgütsel esneklik algılarının diğer akademisyenlere ve özellikle lisans seviyesinde olanlara göre daha fazla olduğu $\left[\mathrm{F}_{(4,235)}=1,550 ; \mathrm{p}<0,05\right]$ görülmüştür. Ele alınan değişkenlerin ortalamalarının ise akademisyenlerin kurum içi statülerine göre anlamlı bir farklılık göstermediği tespit edilmiştir. Bu bulgular özellikle genç yaştaki ve bekar olan akademisyenlerin kuruma yeni girdikleri düşüncesi ile örgüt norm ve kurallarına daha bağlılık gösterdiği şeklinde yorumlanabilir.

Çalışmada, ÖSE'nin sosyal kaytarma ve yenilikçiliğe olan etkilerini ortaya koymak ve geliştirilen hipotezleri test etmek maksadıyla hiyerarşik regresyon analizleri yapılmıştır. Söz konusu analizlerde demografik değişkenlerin etkilerini kontrol altına almak amacıyla ilk aşamada söz konusu demografik değişkenler, daha sonraki aşamada ise bağımsız değişken olan ÖSE değişkeni modele dâhil edilerek, bağımlı değişken olan sosyal kaytarma ve yenilikçilik davranışı üzerindeki etkilerine bakılmıştır. Yapılan regresyon analizlerine ait sonuçlar Tablo 3 'te verilmiştir.

Tablo 3. Sosyal Kaytarma ve Yenilikçiliği Yordayan Örgütsel Sık1lık-Esnekliğin Hiyerarşik Regresyon Analiz Sonuçları

\begin{tabular}{|c|c|c|c|c|}
\hline \multirow{2}{*}{ Bağımsız Değişkenler } & \multicolumn{2}{|c|}{ Sosyal Kaytarma (SK) } & \multicolumn{2}{|c|}{ Yenilikçilik (Y) } \\
\hline & $\beta$ & $\Delta \mathrm{R}^{2}$ & $\beta$ & $\Delta \mathrm{R}^{2}$ \\
\hline 1. Demografik Değişkenler & & ,019 & & 024 \\
\hline Cinsiyet &,- 038 & &,$- 160 *$ & \\
\hline Yaş & ,048 & & ,019 & \\
\hline Medeni Durum &,- 088 & & ,005 & \\
\hline Eüitim &,- 102 & &,- 004 & \\
\hline Statü &,- 010 & & ,007 & \\
\hline$\Delta \mathbf{F}$ & \multicolumn{2}{|c|}{0,879} & \multicolumn{2}{|c|}{1,147} \\
\hline 2. Örgütsel S1kul1-Esneklik (ÖSE) &,- 200 & ,098 &,- 352 &, 116 \\
\hline$\Delta \mathbf{F}$ & \multicolumn{2}{|c|}{$9,105^{* *}$} & \multicolumn{2}{|c|}{$30,848^{* *}$} \\
\hline
\end{tabular}

Tablo 3'te de görüldüğü üzere, sosyal kaytarma ve yenilikçilik genel anlamda ele alınan demografik değişkenler tarafindan yordanmamış (sosyal kaytarma: $\Delta \mathrm{F}=0,879, \Delta \mathrm{R} 2=0,019, \mathrm{p}>0,05$, yenilikçilik: $\Delta \mathrm{F}=1.147, \Delta \mathrm{R} 2=0.024, \mathrm{p}>0,05)$ olmakla birlikte sadece cinsiyetin yenilikçilik davranışını yordadığ $(\beta=-$ $, 160, \mathrm{p}<0,05)$ tespit edilmiştir.

Analiz neticesinde, ÖSE'nin hem sosyal kaytarmayı $(\beta=-, 200, p<0,01)$ hem de yenilikçiliği $(\beta=-, 352$, $\mathrm{p}<0,01)$ negatif ve anlamlı olarak yordadığ1 ortaya konmuştur. Ayrıca ÖSE sosyal kaytarma toplam varyansının \% 9.8'ini, yenilikçilik toplam varyansının ise \%11,6'sını açıklamaktadır. Analizlerle ortaya konan bu bulgular, akademisyenlerin kurumlarına yönelik olarak ÖSE algılamalarının onların görevlerini yaparken sosyal kaytarma ve yenilikçilik davranışlarını anlamlı olarak etkilediğini göstermektedir. Söz konusu etkiler kapsamında, örgütsel sıkılı̆ıın fazla olması akademisyenlerin sosyal kaytarmalarını engellediği ancak esnekliğin ise yenilikçilik davranışlarına olumlu katkılar sağladığ1 şeklinde değerlendirilebilir. Ayrıca bu sonuçlar çalışmanın teorik kısmında geliştirilen Hipotez-1 ve Hipotez-2'yi alt hipotezleriyle birlikte desteklemektedir.

\section{Sonuç ve Öneriler}

Kültür yazınında sıkılık-esneklik konusu son zamanlarda araştırmalara konu olan bir kavram olarak karşımıza çıkmakta ve aynı zamanda da bu çalışmanın temel değişkenlerinden birini oluşturmaktadır. Bu araştırmada, Ankara'daki kamu üniversitelerinde çalışan akademisyenlerin kurumlanna dair algıladıklanı kültürel yapının, onların sosyal kaytarma eğilimlerine ve yenilikçilik davranışlarına nasıl etki ettiği ele alınmış ve incelenmiştir. Örgüt kültürünün kaytarma eğilimi ve yenilikçilik potansiyeli üzerinde etkisi olduğunu ortaya koyan ve sonuçlarının bu çalışmanın sonuçları ile örtüştügüu çalışmalar mevcuttur (Hofstede, 1980; Shane, 1993; Shane vd., 1995; Herbig \& Dunphy, 1998; Jones \& Herbert, 2000; Özeren, 2011; Uğurlu Kara, 2020).

Küresel bir köy haline dönüşen günümüz dünyasinda, teknolojinin gücüyle birlikte birçok disiplinel alan sınırlar ötesi özellik kazanmıştır. Belki de bu şekilde hızla yayılan konuların başında 'biloi’ gelmektedir. 
Bilginin sınırlar ötesi yayılımı nedeniyle örgütler de kendilerini değişime mecbur görmektedirler. $\mathrm{Bu}$ değişime hızla uyum sağlayabilecek, kendi örgüt kültürlerine adapte edebilecek çalışanların mevcudiyetinin örgütleri daha başarllı kılacağ1 düşünülmektedir. Murat ve Açıkgöz’e (2007, s. 5) göre, etkili bir insan kaynakları süreci ile etkili ve istenilen bir örgüt kültürü şekillendirilebilir.

Yükseköğretim kurumlarının görevlerinden birisi de işte bu nitelikli işgücünü yetiştirip topluma kazandırmaktır. Bunun sağlanabilmesi için de üniversite yönetiminin desteği çok önemlidir. Yönetimde yer alan akademisyen yöneticilerin örgütsel kültürel yapıyı göz önünde bulundurarak değişim ve yeniliği desteklemesi, çalışanlar arasında adaleti sağlamak için kaytarma davranışlarını tespit edebilmesi ve bunun önüne geçebilmesinde muhakkak ki bazı faktörler etkili olacaktır (ünvan, çalışma yılı, liderlik tarzları vb.). Gül ve diğerleri (2016) araştırmalarında, örneklem olarak ele aldığ1 üniversitelerden yola çıkarak akademisyen yöneticilerin yenilik ve girişimciliğe önem verdikleri bulgusuna ulaşılmıştır. Sürekli yaşanan değişimler ve rekabet durumları göz önünde bulundurulduğunda akademisyenlere yüklenen misyonun da güncellenmesi gerekmektedir. Bunu yaparken, bu misyondan direkt etkilenecek olan öğrencilerin görüşlerine de başvurulmalıdır, çünkü onlar değişimi yakından izleyen ve kullanan kesim olarak yapacakları katkıyla süreci olumlu yönlendirebileceklerdir. Bireysel yenileşme çabalarının örgütsel yenileşmeyi doğuracağı unutulmamalıdır.

Bahsedildiği üzere, yükseköğretim kurumlarında yöneticilerin yanı sıra, bu yenilikçiliği destekleyecek örgüt kültürünün ve örgüt ikliminin varlığılla akademisyenler bu sürece daha fazla katk1 sağlayabilecektir (Tabak, vd., 2010). Aslında bakıldığında, örgütün esnek veya sıkı kültüre sahip olmasını belirlemede, çalş̧anlarnn rolü büyüktür. Örneğin, akademisyenler kendi kurumlarındaki örgüt kültürünü yaratmakla da mükelleftir. Yaratıcılığ1 ve yeniliği teşvik eden, cesaret uyandıran, risk alabilen davranışlarıyla esnek bir örgüt iklimi oluşturabilirler veya bu durumun tam tersi, belirlenen kalıpların dışına çıkmayarak, sistemin koyduğu kurallar bütününe göre hareket ederek daha sıkı bir örgüt iklimi de oluşturabilirler.

Yenilikçi davranma hususunda, örgütün kültürel yapısı, kültürel değerleri ve buna istinaden yapılan tercih ve uygulamalarının örgütün başarısını etkilemesi kaçınılmazdır. Bu unsurlar örgütten örgüte farklılık gösterebilecek ve buna uygun beklenti ve ihtiyaçlar da değişebilecektir. Ancak bu beklenti ve ihtiyaçlar doğru tespit edilip giderildiğinde, yenilikçi davranışlar cesaret bulup ortaya çıkacaktır. Günümüzde, çalş̧anlar arasında da çok kültürlülügün olması durumu mevcuttur. Burada yöneticilere düşen görev bu çok boyutlu kültür yapısını örgüt kültürü potasında eriterek çalışanlara benimsetilmesidir. Bunun için de çalışanlar arasında iş birliği ve koordinasyon önemlidir. Bu iş birlikteliğinden doğacak sıkıntılardan bir tanesi de bahsedildiği üzere kaytarma davranışlarıdır. Kafes ve Kaya (2017, s. 229) sosyal kaytarma davranışı üzerine yapılmış çalışmaları incelemişler ve kaytarma davranışına etki eden faktörleri şu dört başlık alıında toplamışlardır; kişisel özellikler, durumsal özellikler, grup özellikleri ve kültürel ve toplumsal normlardır. Sünnetçioğlu ve diğerleri de (2014, s. 17-34) örgüt tiplerinin sosyal kaytarma üzerindeki etkisini incelemişler ve sonucunda toplulukçu kültürde sosyal kaytarma davranışının daha az algılandığını bulmuşlardır. Örgütlerin sahip oldukları kültürel yapı sosyal kaytarma davranışına sebep olabileceği gibi bu istenmeyen davranışın ortadan kalkmasına da yardımcı olabileceği düşünülmektedir. Sosyal kaytarma her örgütte olduğu gibi üniversitelerde de büyük bir sorun olmakla beraber, bu tarz sorunların eğitim sistemlerinin gelişim dinamizmini yükselttiği de göz önünde bulundurulmalıdır. Böylesi durumlarda yöneticilerin problem çözme becerileri ile, kaytarma davranışını sergileyen ve bundan etkilenen kişilerin ihtiyaçları doğrultusunda hareket etmesinin süreci daha iyi yönetmesini sağlayacağı düşünülmektedir.

Bu çalışmada değişkenlere dair kurulan hipotezleri test etmek için hiyerarşik regresyon analizleri yapılmıştır. Ulaşılan bulgular, örgütsel sıkılık-esneklik ile sosyal kaytarma ve yenilikçilik davranışları arasında anlamlı ilişkilerin olduğunu göstermektedir. Örgütlerde, çalışanların sıkı bir örgüt kültürü olduğunu algılaması onların sosyal kaytarma davranışlarını azaltırken, esnek kültür algılamaları da onların yenilikçilik davranışlarını arttırmaktadır, dolayısıyla kurulan hipotezler desteklenmektedir.

Ulaşılan sonuçlara paralel olarak, örgütte kabul görmesi beklenen kültürel yapı, iş görenler arasındaki dayanışmayı arttırmalı, gerektiğinde istenmeyen davranışların önünde bir set kurmalı, rekabette üstünlük için yenilik ve yaratıcılık gereken durumlarda cesaret verici olmalıdır, denilebilir. Hangi sektör veya hangi örgüt olursa olsun, rekabette sürekli ilerleme kaydedilmeli, avantaj yaratacak durumlar tespit edilmeli, 
verimlilik ve performans eğrisi sürekli yükseltilmeli ve bunların nasıl yapılacağı konusuna en iyi düzeyde hazırlık yapılmalıdır.

Çalışanların kurumlarının kültürlerine, çalışanların yeterli kapasite ile çalışıp çalışmadıklarına ve yenilikçilik süreçlerine dair algılarının nasıl olduğunun, bu algılanı nelerin etkilediğinin, davranışlarını nasıl şekillendirdiğinin ve bu davranışların kişisel ve örgütsel performansa ne yönde katkı yaptığının araşıtrılması, yöneticilere işlerini kolaylaştıracak katkılar sağlayacaktır. Çünkü yöneticiler bu cevaplarla daha güçlü stratejiler oluşturabilir ve çalışanlarda istendik davranış değişikliği ve kalıcillğı sağlayabilirler. $\mathrm{Bu}$ çalışma ile de bu sorulara kısmen cevap bulunarak alan yazına katkı yapıldığı düşünülmektedir.

Ayrıca, alan yazında bütün değişkenlerin ele alındığı başka bir çalışma olmayışı bir sınırlılık olmakla beraber, bu araştırma ile bir boşluğun kapatılmasının da avantaj yarattı̆̆ı söylenebilir. Ayrıca bu çalışma Ankara ilinde faaliyet gösteren 8 üniversite ele alınarak yapıldığından, Türkiye ölçeğinde kamu ve özel üniversiteleri de kapsayacak şekilde genişletilerek meta çalısmalara dönüştürülmesi daha verimli sonuçlar verebilir. Sonraki çalışmalarda sıkilık-esneklik kültür boyutu ile performans arasındaki ilişkide yenilikçilik davranışının aracılık etkisi, yine sıkılık-esnekliğin yenilikçilik ve girişimcilik üzerindeki etkileri de araştırılabilir.

\section{Extended Abstract}

In the study, it is aimed to reveal the effects of organizational tighness and loosenes on academicians' perceptions of social loafing and innovative behaviors. In the study, hierarchical regression analyzes were conducted in order to reveal the effects of organizational tighness and loosenes on social loafing and innovation and to test the developed hypotheses. The population of the participant included in the research consists of academicians working in a total of 8 public universities in Ankara. In accordance with the ethics of the study and publication in the study, electronic questionnaires were sent to 359 academicians with the easy sampling method in order to reveal the causal relationship between variables and to match the theoretical background of the research. However, 257 of these forms were returned. As a result of the initial evaluation and end analysis, it was determined that the data in 236 questionnaires were suitable for analysis and the study was carried out on the data of 236 academicians.

In these analyzes, in order to control the effects of demographic variables, the demographic variables in question were included in the model at the first stage and the independent variable organizational tighness and loosenes in the next stage, and their effects on the dependent variable, social loafing and innovativeness, were examined. It was determined that there is a moderate relationship between organizational rigidity-flexibility and both social loafing perception and innovative behaviors, but these relationships are negative. Relationships between organizational tighness and loosenes and academicians' perception of social loafing and innovative behaviors are negative and significant. When the averages of academicians' perceptions of variables are evaluated, it is seen that the tighness-looseness variable is slightly above the average. This situation indicates that academics generally see their institutions closer to a tight structure. When the social loafing perceptions of academicians are examined, it is seen that it is on average. This situation shows that academics do not perceive a high level of loafing behavior in their institutions. Again, it is seen that academicians' perceptions of innovative behavior are at a moderate level. This shows that academics perceive their institutions to be moderately open to innovation. In addition, the significant differences between the means of demographic variables (gender, age, marital status, education, status) on other variables were analyzed by t-test and one-way analysis of variance (ANOVA). According to the analysis results, it was determined that the strictness-flexibility, social loafing and innovativeness behaviors of the variables of the academicians showed significant differences according to some demographic variables discussed in the study. In this context; male academicians exhibit more innovative behavior than female academicians, academicians aged 25 and under have a higher average score of organizational tightness than other age groups, married academicians have a higher level of organizational looseness than single academicians, doctoral and higher education according to the level of education It has been observed that the organizational looseness perceptions of the academicians with a high level of education are higher than the other academicians and especially those at the undergraduate level. It was determined that the averages of the variables considered did not differ significantly according 
to the in-house status of the academicians. These findings can be interpreted as especially young and single academics with the thought that they have recently entered the institution and show more adherence to the norms and rules of the organization. Findings show that there are significant relationships between organizational firmness-flexibility and social loafing and innovativeness. In organizations, employees' perception of a strict organizational culture decreases their social loafing behaviors, while looseness culture perceptions increase their innovative behavior, so the established hypotheses are supported.

\section{Kaynakça}

Au, K. (1999). Intra-cultural variation: Evidence and implications for international business. Journal of International Business Studies, 30, 799-813.

Aydıntan, B., \& Göksel, A. (2012). Cameron-Freeman-Quinn örgüt kültürü tipolojileri ekseninde örgüt kültürü farklılaşma dinamikleri. Niğde Üniversitesi İIBF Dergisi, 5(2), 53-62.

Bacanl, H., İlhan, T., \& Aslan, S. (2009). Beş faktör kuramına dayalı bir kişilik ölçeğinin geliştirilmesi: Sifatlara dayalı kişilik testi (SDTK). Türk Ë̆itim Bilimleri Dergisi, 7(2), 261-279.

Balcı, O. (2017). Kalabalıkta saklanma: Sosyal kaytarma. Akademik Sosyal Araştırmalar Dergisi 5(46), 373387.

Bedük, A. Alodalı M.F., \& Güneş, İ. (2003). Yenilikçilik, yaratıcılık ve bilgi yönetimi. Kal-Der Forum, 3(12), İstanbul.

Burgelman, R.A., Maidique, M. A., \& Wheelwright, S. C. (1996). Strategic management of technology and innovation. Times Mirror Higher education Group Inc. U. S. A.

Büyüköztürk, Ş. (2007). Sosyal bilimler için veri analiz̧ el kitabı. Ankara: Pegem Yayıncıllk.

Büyüköztürk, Ş., Çakmak, E.K., Akgün, Ö.E., Karadeniz, Ş., \& Demirel, F. (2008). Bilimsel araştırma yöntemleri. Geliştirilmiş 2. Baskı, Ankara: Pegem Akademi.

Carpender, S. (2000). Effects of cultural tightness and collectivism on self-concept and causal attributions. Cross-Cultural Research, 34, 38-56.

Chan, D. K.S., Gelfand, M. J., Triandis, H. C., \& Tzeng, O. (1996). Tightness-looseness revisited: Some preliminary analyses in Japan and the United States. International Journal of Psychology, 31,1-12.

Chen, X. (2000). Social and emotional development in chinese children and adolescents: $A$ contextual cross-cultural perspective. (Edt. Columbus, F.). In: Advances in Psychology Research. Huntington, NY: Nova Science Publishers, Inc., 229-251.

Chen, T. Y., Chang, P. L., \& Yeh, C. W. (2003). The study of career needs, career development programmes and job satisfaction levels of $\mathrm{r} \& \mathrm{~d}$ personnel: The case of taiwan. The International Journal of Human Resource Management, 14(6), 1001- 1026.

Ceylan, A., \& Özbal, S. (2005). Yenilikçi iş davranışı ve çalışanların adalet algıları arasındaki ilişkiler üzerine bankacılık sektöründe yapılan bir çalışma. Istanbul Üniversitesi Siyasal Bilgiler Fakültesi Dergisi, 32, 167 184.

Çankaya, İ. H. (2010). Öğrencilerin sosyal sorumluluk düzeylerinin artırılmasında okulun rolüne ilişkin yönetici görüşleri. Că̆daş Ĕ̈itim Dergisi, 19(2):378-380.

Desouza, K.C., Dombrowski, C., Awazu, Y., Baloh, P., Papagari S., Jha, S., \& Ki, J. Y. (2009). Crafting organizational innovation processes. Innovation, Management, Policy \& Practice, 11(1), 6-33.

Dobni C. B. (2006). The innovation blueprint, Business Horizons, 49.

Earley, P. C. (1993). East meets west meets mideast: Further explorations of collectivistic and individualistic work groups. Academy of Management Journal, 36(2), 319-348.

Elenkov, D.S., \& Manev I.M. (2009). Senior expatriate yeadership's effects on innovation and the role of cultural intelligence. Journal of World Business, 44.

Erarslan, D. (2011). İse alım sürecinde iç kaynaklardan yararlanma politikası ve örgüte bağhlık ilişkisinin incelenmesine yönelik bir araştırma. Yayımlanmamış Yüksek Lisans Tezi, Marmara Üniversitesi Sosyal Bilimler Enstitüsü İşletme Ana Bilim Dalı, İstanbul.

Ertürk, R., \& Argon, T. (2019). Ögretmen Görüslerine Göre Okullarda Takım Calısmaları ve Sosyal Kaytarma. 28. Uluslararası Eğitim Bilimleri Kongresi Bildiri Kitabı içinde (s. 491-513). Ankara. 
Gelfand, M. J., Nishii, L. H., \& Raver, J. L. (2006). On the nature and importance of cultural tightness and looseness. Journal of Applied Psychology, 91(6), 1225-1244.

Gelfand, M. J., Nishii, L. H., \& Raver, J. L. (2007). On the nature and importance of cultural tightnesslooseness. CAHRS Working Paper Series, 1-59. Ithaca, NY: Cornell University, School of Industrial and Labor Relations, Center for Advanced Human Resource Studies. http://digitalcommons.ilr.cornell.edu/cahrswp/462 [Erişim Tarihi: 10.03.2020]

Gelfand, M. J., Raver, J. L., Nishii, L., Leslie, L. M., Lun, J., Lim, B. J., Duan, L., D’Amato, A., Almaliach, A., Ang, S., Aycan, Z., Arnadottir, F., Biasoli, Z. M. M., Boehnke, K., Boski, P., Cabecinhas, R., Chan, D., Chhokar, J., Ferrer, M., Fischlmayr, I. C., Fischer, R., Fülöp, M., Georgas, J., Kashima, E. S., Kashima, Y., Kim, K., Lempereur, A., Marquez, P., Othman, R., Overlaet, B., Panagiotopoulou, P., Peltzer, K., Perez-Florizno, L. R., Petrovna, L., Realo, A., Schei, V., Schmitt, M., Smith, P. B., Soomro, N., Szabo, E., Taveesin, N., Toyama, M., Vliert, E.V., Vohra, N., Ward, C., Yamaguchi, S., \& Yan, X. (2010). The difference between 'tight' and 'loose' societies revisited: ecological, socio-political, and societal correlates of tightnesslooseness in modern nations. http://www.gelfand.umd.edu/science.pdf [Erişim Tarihi: 15.03 .2020$]$.

Gelfand M. J., Raver, J. L., Nishii, L., Leslie, L.M., Lun, J., Lim, B.J., Duan, L., Almaliach, A., Ang, S., Arnadottir, J., Aycan, Z., Boehnke, K., Boski, P., Cabecinhas, R., Chan, D., Chhokar, J., D’Amato, A., Ferrer, M., Fischlmayr, I. C., Fischer, R., Fülöp, M., Georgas, J., Kashima, E. S., Kashima, Y., Kim, K., Lempereur, A., Marquez, P., Othman, R., Overlaet, B., Panagiotopoulou, P., Peltzer, K., Perez-Florizno, L. R., Ponomarenko, L., Realo, A., Schei, V., Schmitt, M., Smith, P. B., Soomro, N., Szabo, E., Taveesin, N., Toyama, M., Vliert, E.V., Vohra, N., Ward, C., \& Yamaguchi, S. (2011). Differences between tight and loose cultures: A 33-nation study. Science. 332: 1100.

George, J. M. (1992). Extrinsic and intrinsic origins of perceived social loafing in organizations. Academy of Management Journal, 35, 191-202.

Gül, K., Gül, M., \& Saatçi, G. (2016). Akademik Yöneticilerin Yönetsel Yetkinlik Düzeylerinin Araştırılması; Balıkesir ve Bursa'da Ampirik Bir Çalışma. Balıkesir Üniversitesi Sosyal Bilimler Enstitïsü Dergisi, 19(35), 283-301.

Herbig, P., \& Dunphy, S. (1998). Culture and innovation. Cross Cultural Management, 5(4), 13-21.

Hofstede, G. (1980). Culture's consequences: international differences in work related values. Beverly Hills, Calif.: Sage

Hofstede G. (1993). Cultural constraints in management theories. The Academy of Management Perspectives; 7(1), 81-94.

Hogg, M. A., \& Vaughan G. M. (2005). Sosyal psikoloji (Çev. Yıldız, İ. ve Gelmez, A.). İstanbul: Ütopya Yayınlar1 No:150, 1-811.

Hogg, M. A., \& Vaughan G. M. (2011). Social psychology. (4th Ed.). UK: Pearson Education, 1-777.

Holzer, S. (2000). Schedule in Japan. AnimaniA, 3, 72-75.

İnternet: https://medium.com/innocentrumblog $/ \mathrm{k} \% \mathrm{C} 3 \% \mathrm{BCresel}-\mathrm{i} \% \mathrm{CC} \% 87$ novasyon-endeksi-2019sonu $\% \mathrm{C} 3 \% \mathrm{~A} 7 \mathrm{lar} \% \mathrm{C} 4 \% \mathrm{~B} 1-\mathrm{a} \% \mathrm{C} 3 \% \mathrm{~A} 7 \% \mathrm{C} 4 \% \mathrm{~B} 1 \mathrm{kland} \% \mathrm{C} 4 \% \mathrm{~B} 1-5 \mathrm{c} 35495692 \mathrm{~d} 6$ [Erişim Tarihi: 09.10.2020].

Jensen-Campbell, L. A., \& Malcolm, K. T. (2007). The importance of conscientiousness in adolescent interpersonal relationships. Personality and Social Psychology Bulletin, 33(3), 368-383.

Johnson, J. R. (1998). Embracing change: A leadershp model for the learning organization. International Journal of Training and Development, 2(2), 141-150.

Jones, G.K., \& Herbert, J. (2000). National culture and innovation: İmplications for locating global r\&d operations. Management International Review. 40(1), 11-39.

Jong, J. P. (2007). Individual innovation: The connection between leadership and employees' innovative work behavior. Amsterdam: Zoetermeer: EIM

Jucevičlus, G. (2007). İnnovation culture: Constable universality of the concept. Kaunas University of Tecnology, Social Sciences, 4(58).

Judge, W. Q., Fryxell, G. E., \& Dooley, R. S. (1997). The new task of r\&d management: Creating goaldirected communities for innovation. California Management Review, 39(3), 72-85. 
Kaasa, A., \& Vadi, M. (2008). How does culture contribute to innovation? Evidence from european countries, University of Tartu, Faculty of Economics and Business Administration.

Kafes, M., \& Kaya, D. (2017). Sosyal kaytarma davranışı üzerine yapılmış çalışmaların incelenmesi. Türk İslam Dünyası Sosyal Arastırmalar Dergisi, 4-11.

Karau, S. J., \& Williams, K. D. (1993). Social loafing: A meta-analytic review and theoretical integration. Journal of Personality and Social Psychology, 65(4), 681-706.

K1lınç, I. (2020). Örgütsel sıkılık ve esnekliğin örgütsel yenilikecilik üzerine etkisi ve dönüstürüiü liderliğin aracılık rolï. Yayımlanmamış Yüksek Lisans Tezi, İzmir Kâtip Çelebi Üniversitesi Sosyal Bilimler Enstitüsü İşletme Ana Bilim Dalı, İzmir.

K1lınçarslan, Ö. (2018). Okul müdürlerinin algılarna göre ögrretmenlerin sosyal kaytarma davranıslar. Necmettin Erbakan Üniversitesi Eğitim Bilimleri Enstitüsü İşletme Ana Bilim Dalı, Konya.

Kilmann, R. J., Saxton, M. J., \& Serpa, R. (1985). Gaining control of the corporate culture. San Francisco: Jossey-Bass.

Köksal, K., Eroğluer, K., \& Yapar, H. (2018). Psikolojik sözleşme ihlalinin yenilikçi davranışa etkisi: Örgütsel sessizliğin rolü: savunma sanyiinde bir uygulama. Uluslararası İktisadi ve İdari İncelemeler Dergisi, 17. UIK Özel Sayisı.

Krauss, R. M., \& Chiu, C. (1998). Language and social behavior. The Handbook of Social Psychology, 1(2), 41-88.

Latane, B., Williams, K., \& Harkins, S. (1979). Many hands make light the work: The causes and consequences of social loafing. Journal of Personality and Social Psychology, 37(6), 822-832.

Liu, S. S., Luo, X., \& Shi, Y. (2002). İntegrating customer orientation, corporate entrepreneurship, and learning orientation in organizations-in-transition: an empirical study. International Journal of Research in Marketing. 19, 367-382.

Luecke, R. (2011). Iss dünyasında yenilik ve yaratıcılık (çev.Turan Parlak). İstanbul: İş Bankası Kültür Yayınları.

Mehta, M. (2006). Growth by design: How good design drives company growth. Ivey Business Journal

Meydan, C.H., \& Şeşen, H. (2011). Yapısal eşitlik modellemesi Amos uygulamalar, Detay Yayıncllı, Ankara.

Moskowitz, G. B. (1993). Individual differences in social categorization: The influence of personal need for structure on spontaneous trait inferences. Journal of Personality and Social Psychology, 65, 132-142.

Mulvey, P. W., \& Howard J. K. (1998). The impact of perceived loafing and collective efficacy on group goal processes and group performance. Organizational Behavior and Human Decision Processes, 74(1), 6287.

Murat, G., \& Açıkgöz, B. (2007). Yöneticilerin örgüt kültürü alg1lamalarına ilişkin bir analiz: Zonguldak Karaelmas Üniversitesi örneği. ZKÜ Sosyal Bilimler Dergisi, 3(5), 1-20.

Nicholson, A. (2012). Perceptions of the peer evaulation system: Relation with social loafing behaviours. Concordia University, Master Thesis.

Öneren, M., Demirel, E. N., \& Kartal, C. (2019). Yükseköğretim kurumlarında sosyal kaytarma davranışının incelenmesi: Bir kamu üniversitesi örneği. Anemon Mus Alparslan Üniversitesi Sosyal Bilimler Dergisi, 7(1) 309-318.

Özeren, E. (2011). Örgüt kültüründe yeni bir boyut olan sıkılık-esneklik ile örgütsel yenilikçilik ilişkisi: Türk ve İtalyan mermer sektöründe karşılaştırmalı bir araştırma. Yayımlanmamış Yüksek Lisans Tezi, Dokuz Eylül Üniversitesi Sosyal Bilimler Enstitüsü İşletme Ana Bilim Dalı, İzmir.

Pelto, P. (1968). The difference between 'tight' and 'loose' societies. Transaction, 5, 37-40.

Sakal, Ö., \& Macit, R. (2018). S1k1lik-esneklik ve performans: psikolojik güçlendirmenin arac1 rolü. Social Sciences Studies Journal, 4(21), 3352-3362.

Senge, P. M. (2004). The fifth discipline: the art and practice of learning organization, currency doubleday. http://www.scribd.com/doc/8057347/Peter-SengeThe-Fifth-Discipline-1 [Erişim Tarihi: 25.03.2020]

Shane, S. (1993). Cultural influences on national rates of innovation. Journal of Business Venturing, 8(1), $59-73$ 
Shane, S., Venkataraman, S., \& MacMillan, I. (1995). Cultural differences in innovation championing strategies. Journal of Management. 21(5), 931-952

Sünnetçioğlu, S., Korkmaz, H., \& Koyuncu, M. (2014). Konaklama işletmelerinde algilanan örgüt kültür tipinin çalışanların sosyal kaytarma davranışlarını algılamasına etkisi üzerine bir araştırma. Mustafa Kemal Üniversitesi Sosyal Bilimler Enstitïsï Dergisi, 11(28), 17-34.

Şeşen, H., \& Kahraman, Ç. A. (2014). İş arkadaşlarının sosyal kaytarmasının, bireyin iş tatmini, örgütsel bağlllık ve kendi kaytarma davranışlarına etkisi. Iss ve Insan Dergisi, 1(1), 43-51.

Tabak, A., Erkuş, A., \& Meydan, C. H. (2010). Denetim odağ1 ve yenilikçi birey davranışları arasındaki ilişkiler: belirsizliğe tolerans ve risk almanın aracilık etkisi. Anadolu Üniversitesi Sosyal Bilimler Dergisi, 10(1), 159-176.

Toh, S. M., \& Leonardelli, G. J. (2012). Cultural constraints on the emergence of women as leaders. Journal of World Business, 47(4), 604-611.

Triandis, H. C. (1989). The self and social behavior in differing cultural contexts. Psychological Review, 96, 506-520.

Tsaw, D., Murphy, S., \& Detgen, J. (2011). Social loafing and culture: does gender matter?. International Review of Business Research Papers, 7(3), 1-8.

Wallach, E. J. (1983). Individual and organizations: The cultural match, training and development journal, USA.

Wang C. L., \& Ahmed P. K. (2004). The development and validation of the organizational innovativeness construct using confirmatory factor alalysis. European Journal of Innovation Management, 7(4).

Wasti, A., \& Fişs A. M. (2010). Örgüt kültüründe sıkllık-esneklik boyutu ve kurumsal girişimciliğe etkisi. Yönetim Arasttrmalar Dergisi, 10, 11-32.

Westwood R., \& Low, D. R. (2003). The multicultural muse: Culture, creativity and innovation, international. Journal of Cross Cultural Management, 3(2), 235-259.

Williams, K. D., Karau, S. J., \& Bourgeois, M. J. (1993). Working on collective tasks: Social loafing and social compensation. (Edt. Hogg, M. and Abrams, D.). In: Group motivation: Social psychological perspectives. New York: Harvester Wheatsheaf, 130-148.

Yamamato, G. (2020). Girişimci yenilikeçi üniversite. Üniversite Araștrmalar Dergisi, 3(1), 44-48.

Yeşil, S. (2012). Türkiye'nin ulusal kültürel özellikleri ve yenilikçilik potansiyeli arasındaki ilişki açısından bir değerlendirme. Mustafa Kemal Üniversitesi Sosyal Bilimler Enstitïsü Dergisi, 9(17). 33-62

Yuan, F., \& Woodman, R. (2010). Innovative behavior in the workplace: The role of performance and 1mage outcome expectations. Academy of Management Journal, 53(2), 323-342.

Zhang Y., \& Lie Y. (2012). An empirical study on innovative culture from the view of educational factors, international conference on future electrical power and energy systems, Energy Procedia. 